\title{
Secondary Neoplasms of the Esophagus
}

\author{
Farooq P. Agha \\ Department of Radiology, University of Michigan Hospitals, Ann Arbor, Michigan, USA
}

\begin{abstract}
A review of 62 cases of esophageal involvement by secondary neoplasms is reported. The common routes of esophageal involvement are by direct extension of the tumor from the contiguous or adjacent organs $(45.2 \%)$, via mediastinal nodes $(35.5 \%)$, and hematogenous spread from a distant primary $(19.3 \%)$. In the first 2 modes of esophageal involvement, the diagnosis is usually obvious but hematogenous metastases to the esophagus usually pose a diagnostic challenge. $\mathrm{Ra}-$ diologically, hematogenous metastases show a spectrum of features consisting of a short segment of progressive stricture with normal to minimally irregular mucosa, a submucosal mass with or without ulceration, a polypoid mass or masses, and defects in esophageal motility including secondary achalasia. Since endoscopy and biopsy have limited diagnostic yield, radiologic diagnosis plays a key role in the diagnosis of secondary neoplasms of the esophagus irrespective of their mode of spread to the esophagus.
\end{abstract}

Key words: Esophagus, secondary neoplasms.

The incidence of esophageal involvement by secondary neoplasms has been reported as $3.2 \%$ in autopsy studies of patients with cancer [1]. In most instances there is direct invasion by the primary tumor from adjacent or contiguous organs [2]. Metastatic involvement of the esophagus from a distant primary lesion is rare. The clinical and radiographic manifestations of a secondary neoplasm may simulate a primary malignant tumor or a benign process [3]. Although radiologic features show significant overlap with those of prima-

Address reprint requests to: Farooq P. Agha, M.D. at present address: Department of Diagnostic Radiology, Evanston Hospital - Northwestern University, 2650 Ridge Avenue, Evanston, IL 60201, USA ry esophageal tumors, certain distinctive features suggest the diagnosis of secondary neoplasm in an appropriate clinical setting.

\section{Materials and Methods}

Between January, 1980, and December, 1985, 62 patients with metastatic esophageal involvement were identified by the medical information and tumor registry department at the University of Michigan Medical Center, Ann Arbor. The medical records, radiographic studies, and available pathologic material, including autopsy reports, were reviewed. Esophageal involvement by direct spread occurred in 28 patients $(45.2 \%)$, via mediastinal nodal spread in 22 patients $(35.5 \%)$, and by hematogenous spread in 12 patients $(19.3 \%)$. This information was derived after careful analysis of all clinical, radiologic, pathologic, and autopsy data.

To determine the frequency of esophageal secondary neoplasms, a comprehensive data search for total numbers of cases of cancers of the stomach, hypopharynx, larynx, lung, breast, and thyroid during the same time period (1980-1985) was conducted and cross-referenced with cases of esophageal metastatic involvement. This information is summarized in Table 1.

The diagnosis of secondary neoplasms of the esophagus was established by endoscopic biopsy in 33 patients, by mediastinal biopsy in 14 , and by autopsy in 15 . Of 50 patients who underwent endoscopy and biopsy, 28 had positive biopsies for malignancy. Among 12 patients with hematogenous metastasis who underwent endoscopic biopsies, only 3 had positive biopsies for tumor.

Fifty patients had barium esophagrams. Of these, 25 had single-contrast and 25 had double-contrast studies. Twelve patients had multiple serial esophagrams. Twenty patients had computed tomograms of the chest and abdomen.

Table 1. Incidence of esophageal metastasis (1980-1985) in 58 patients

\begin{tabular}{lccc}
\hline $\begin{array}{l}\text { Primary } \\
\text { malignant tumor }\end{array}$ & $\begin{array}{l}\text { No. } \\
\text { of patients }\end{array}$ & $\begin{array}{l}\text { Esophageal } \\
\text { metastases }\end{array}$ & $\begin{array}{l}\text { Percentage } \\
\text { incidence }\end{array}$ \\
\hline Stomach & 202 & 21 & 10 \\
Larynx & 300 & 2 & 0.66 \\
Hypopharynx & 186 & 2 & 1.0 \\
Lung & 2,026 & 23 & 1.0 \\
Breast & 543 & 6 & 1.1 \\
Thyroid & 260 & 4 & 1.5 \\
\hline
\end{tabular}




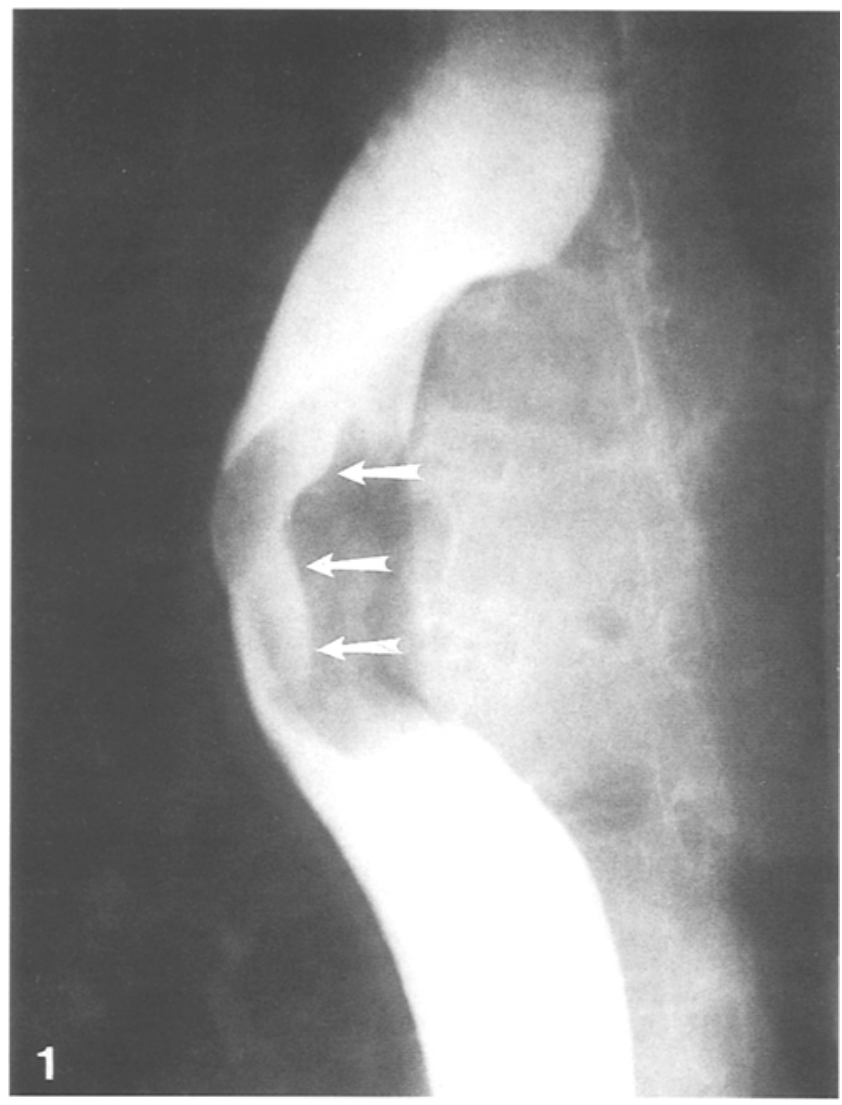

Fig. 1. Anteroposterior radiograph of the esophagus shows a large extramucosal mass invading the esophagus, caused by metastatic breast carcinoma to the mediastinal lymph nodes. A long vertical linear ulceration is present (arrows).

Fig. 2. A Lateral radiograph of the esophagus shows a highgrade midesophageal stricture with nodularity. The esophagus is slightly dilated and the stricture is eccentrically located. An esophageal "jet phenomenon" is present (arrows). B A CT scan at the level of the stricture shows marked thickening of the esophageal wall (arrow) with severe narrowing of the esophageal lumen. A nasogastric tube is present in the esophagus. The primary was a bronchoalveolar cell carcinoma of the lung.
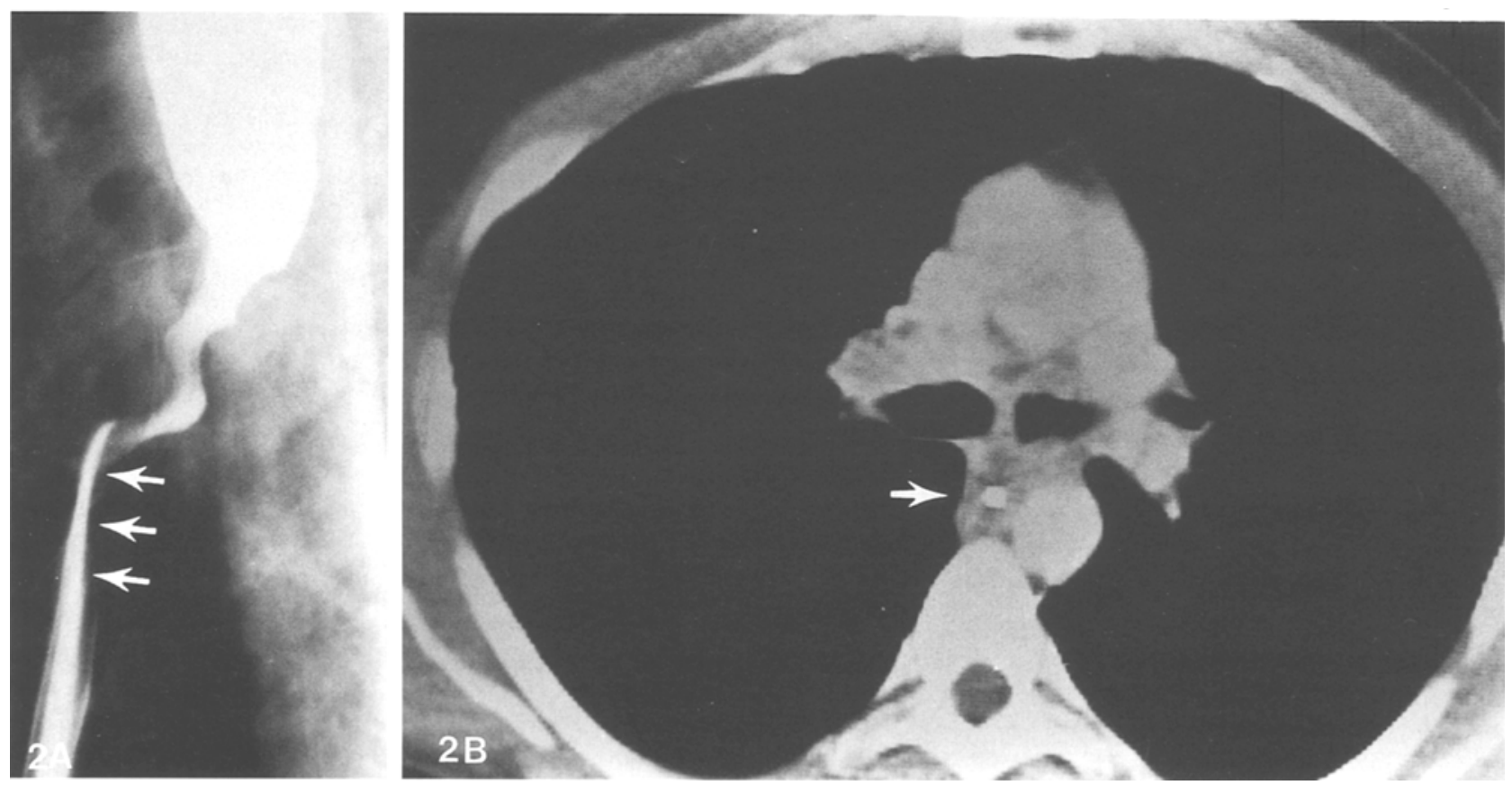

\section{Results}

\section{Clinical Features}

There were 40 men and 22 women, aged $33-78$ years, with a median age of 59 years. The primary malignant tumors were located in the stomach (21 patients), lung (23), breast (6), thyroid (4), larynx (2), hypopharynx (2), and colon, cervix, urinary bladder, and prostate (1 each). Hematogenous spread to the esophagus was infrequent. Pri- 


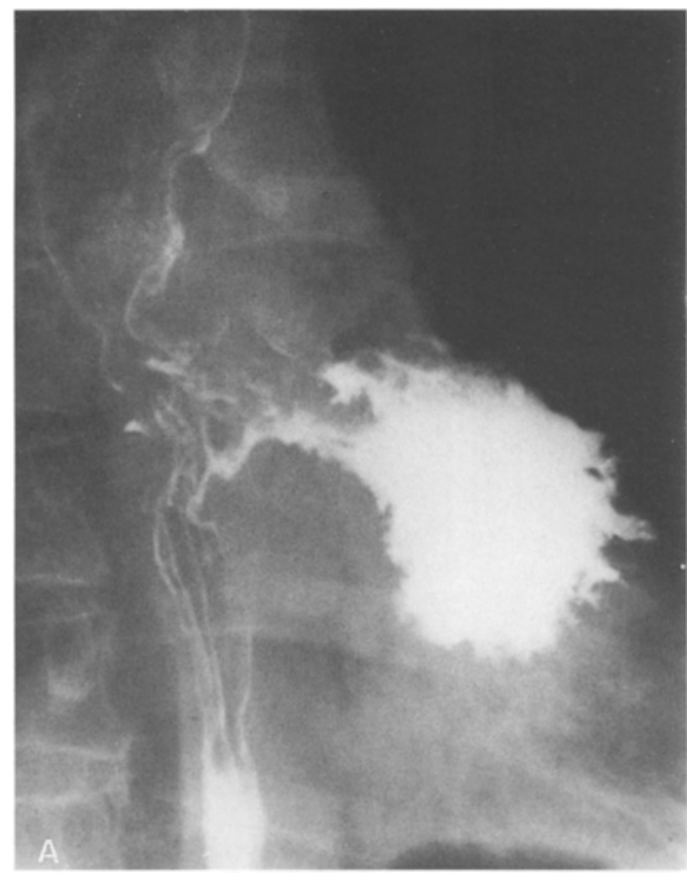

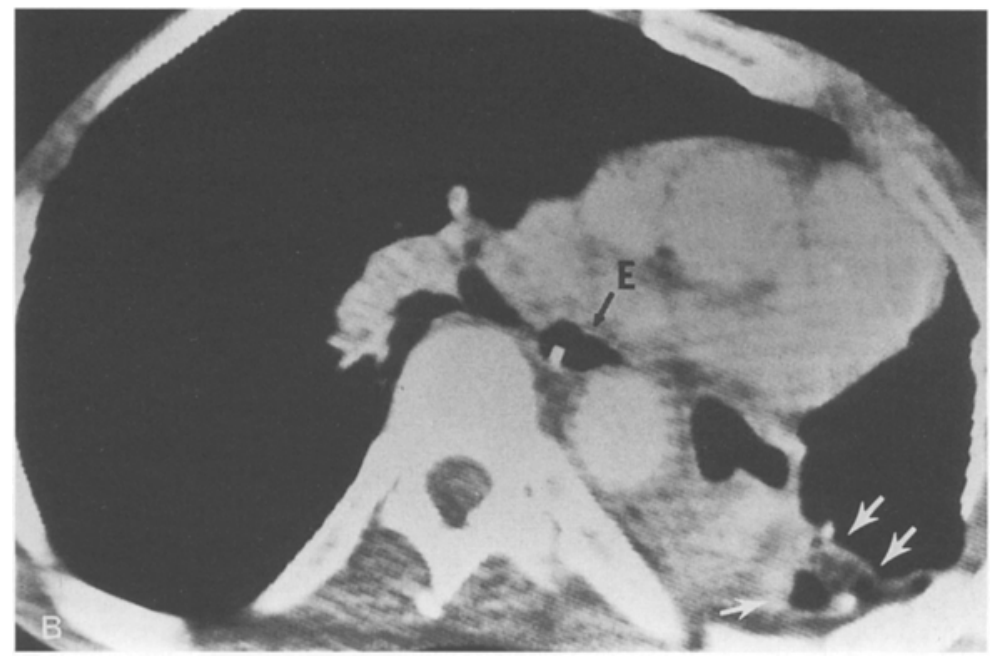

Fig. 3. A An esophagram shows an ulcerative mass in the distal esophagus with esophagopulmonary fistula due to necrotic bronchogenic carcinoma of the left lower lobe. Barium is in the necrotic pulmonary tumor mass.

B A CT scan shows air in the left lower lobe mass (arrows), resulting from the esophageal communication demonstrated by the barium swallow ( $E$, dilated esophagus with nasogastric tube). mary cancers of the breast, thyroid, cervix, bladder, and prostate were responsible for hematogenous metastases to the esophagus.

Fifty percent of the patients complained of progressive dysphagia for 2-4 months. Three patients with lung cancer had odynophagia. The second most common complaint was weight loss of $6.8-18.2 \mathrm{~kg}$. Three patients had hemoptysis, 2 had hematemesis, and 1 had melena.

\section{Radiologic Features}

Patients with esophageal involvement by contiguous tumors showed typical malignant radiologic features indistinguishable from those of a primary esophageal carcinoma. However, the adjacent primary tumor, such as those in the gastric cardia, hypopharynx, and larynx, was obvious and the diagnosis posed no problem. Esophageal involvement from the mediastinal lymph nodes caused nodular indentation, displacement, and compression of the esophagus initially. With progressive nodal enlargement, erosion and even mucosal ulceration of the esophagus were seen (Fig. 1). With circumferential involvement of the esophagus, progressive luminal narrowing and stricture formation occur (Fig. 2). This route of spread was commonly seen in lung and breast cancer cases. Four patients developed esophagobronchial or esophagopulmonary fistulae (Fig. 3). A secondary form of achalasia was noted in 5 patients; 4 had primary gastric cardiac carcinoma and 1 had metastatic co- lon carcinoma to the gastroesophageal region (Fig. 4).

The most salient feature of hematogenous metastases to the esophagus was a short, progressive stricture $(2.5-3 \mathrm{~cm})$ with a slightly irregular mucosal contour and no mucosal ulceration (8 patients) (Fig. 5). The stricture was often eccentrically located (3 patients). Occasionally, longer strictures $(4-6 \mathrm{~cm})$ were seen (2 patients) (Fig. 6). A submucosal mass was noted in 1 patient (Fig. 7). One patient developed severe esophageal dysmotility due to metastases involving the myenteric plexus from carcinoma of the prostate. Review of the computed tomographic studies available in 20 patients revealed esophageal wall thickening in 6 (Fig. 2B), mediastinal mass in 3 , and an esophagopulmonary fistula with a pulmonary necrotic mass in 1 (Fig. 3B).

The radiologic diagnosis of esophageal involvement was accurately suggested in 25 of 28 patients $(89.3 \%)$ with direct spread, 16 of 22 patients $(72.7 \%)$ with mediastinal spread, and 8 of 12 patients $(68.2 \%)$ with hematogenous spread. The overall accurate diagnosis was suggested in $78 \%$ of patients.

\section{Discussion}

Esophageal involvement by metastatic tumors may occur by direct tumor extension from contiguous organs, through mediastinal lymph nodes containing tumor, and via hematogenous spread [4]. The 

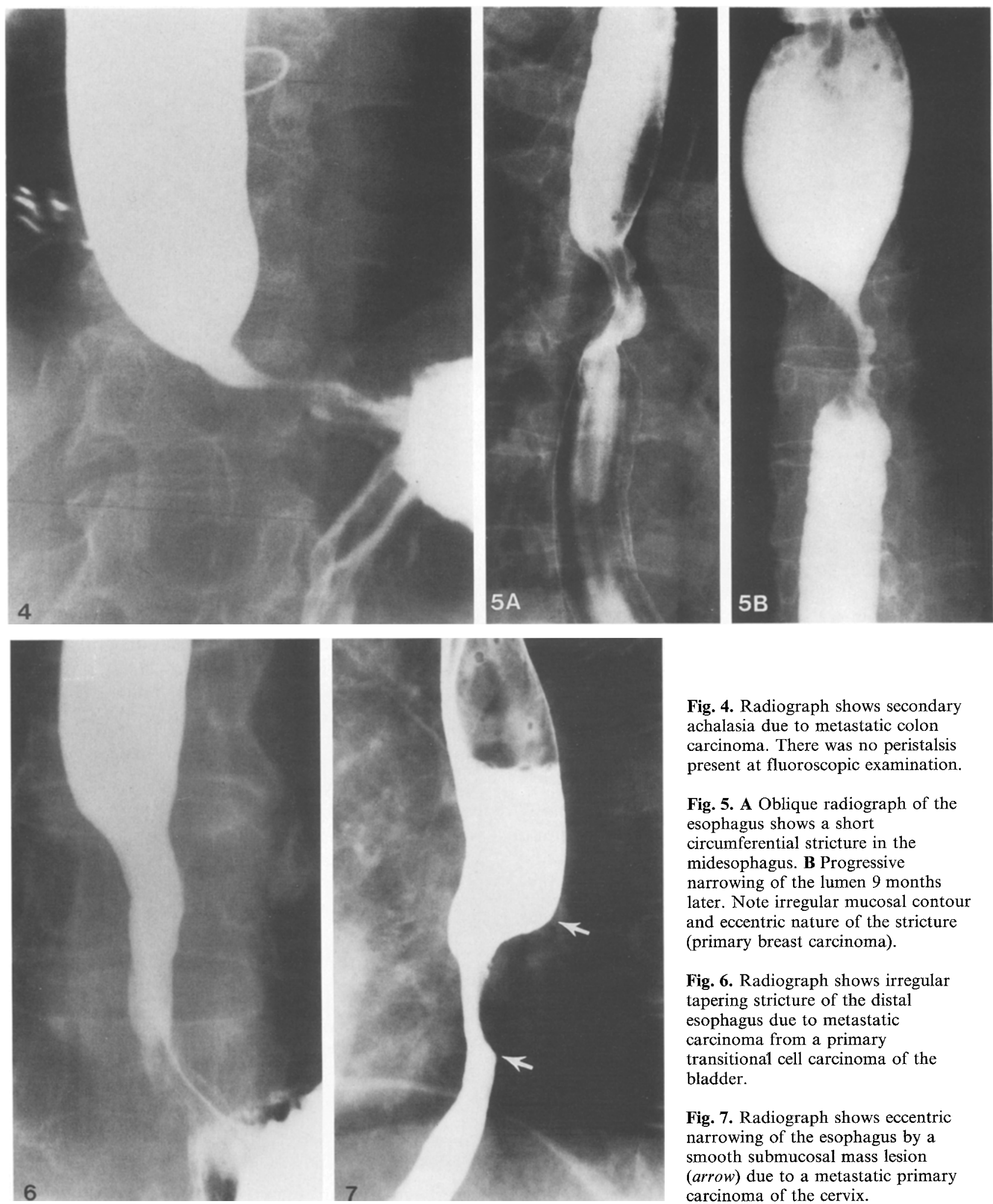

Fig. 4. Radiograph shows secondary achalasia due to metastatic colon carcinoma. There was no peristalsis present at fluoroscopic examination.

Fig. 5. A Oblique radiograph of the esophagus shows a short circumferential stricture in the midesophagus. B Progressive narrowing of the lumen 9 months later. Note irregular mucosal contour and eccentric nature of the stricture (primary breast carcinoma).

Fig. 6. Radiograph shows irregular tapering stricture of the distal esophagus due to metastatic carcinoma from a primary transitional cell carcinoma of the bladder.

Fig. 7. Radiograph shows eccentric narrowing of the esophagus by a smooth submucosal mass lesion (arrow) due to a metastatic primary carcinoma of the cervix. 
first of these is the most common and is usually seen with tumors of the gastric fundus, hypopharynx, and larynx [2]. Contiguous spread of tumor to the distal esophagus from carcinoma of the stomach is well known [5-7] and it is common for carcinoma of the gastric cardia to present with esophageal symptoms initially. Direct esophageal extension of an adjacent tumor usually occurs by lymphatic spread within the esophageal wall through a subepithelial lymphatic plexus in the mucosa that anastomoses freely with another plexus in the submucosa, muscularis, and adventitia [8]. Carcinoma of the hypopharynx and larynx may extend to the cervical esophagus in a similar fashion. In most instances when the esophagus is involved by direct tumor extension, the primary site is apparent $[2,9,10]$.

Involvement of the esophagus by tumor-containing mediastinal lymph nodes is the second most common route of esophageal invasion by metastatic tumors. Autopsy reports have shown that $4 \%$ of patients with carcinoma of the lung [11] and $9 \%$ of those with breast carcinoma [12] had metastatic esophageal tumor. Although lung and breast carcinomas are the sources of most of the tumors, any metastatic mediastinal tumor may invade the esophagus secondarily [13-17]. Generally, metastatic esophageal involvement by tumors located below the diaphragm occurs via mediastinal spread and sometimes by direct extension to the abdominal segment of the esophagus, as in the case of pancreatic carcinoma [15].

Hematogenous metastases to the esophagus are rare and may occur from cancers of the pancreas, testis, eye, tongue, bone, liver, kidney, uterus, skin, synovium, and prostate [3, 14-25]. The present study adds cancers of the cervix, urinary bladder, and breast to this list. Metastatic melanoma [26-28] and lymphoma [29] involving the esophagus secondarily have also been reported.

In a review by Garusi and Donati [30] of 82 instances of metastasis to the esophagus, the breast was the proven source in 28 cases, the pharynx in 26 , the stomach in 10 , and the lungs in 3 , with a wide variety of other sources causing the remainder.

Excluding gastric carcinoma, involvement of the esophagus by metastases from malignant tumors of other organs is infrequent. Torensen [1] reviewed 26 patients in whom the esophagus was involved by metastatic tumors; the primary sites were trachea or bronchus in 8 , stomach in 7 , larynx 4 , breast 2 , pancreas 2 , testis 1 , mediastinal nodes 1 , and an unknown location in 1 . His $3.2 \%$ incidence of esophageal involvement by metastatic tu- mor was derived from a large autopsy series. Sanborn et al. [13], analyzing neoplasms metastasizing to the mediastinum, found that carcinomas of the breast, lung, esophagus, and stomach predominated, but primary tumors of every organ were encountered. They concluded that virtually any malignant tumor might metastasize to the mediastinal lymph nodes. Thus any such tumor involvement of the mediastinal nodes may also involve the esophagus.

The majority of patients with primary esophageal carcinoma present with a clinical picture including dysphagia, regurgitation, substernal distress, and weight loss, and show characteristic radiologic features $[6,7,31]$. With the exception of gastric carcinoma, metastases to the esophagus infrequently produce symptoms. There are very few early signs of invasion of the esophageal wall from without and of metastatic intramural growth. Dysphagia may be a patient's first symptom of metastatic carcinoma of pulmonary origin $[9,10$, 32]. Occasionally, dysphagia may be a presenting symptom in tumors of nonpulmonary origin [3, $4,19,33]$. Usually, dysphagia develops a considerable time after the site of the primary tumor has been established. In cases of carcinoma of the breast, dysphagia develops many years after mastectomy. A review of 44 cases revealed that the mean interval from mastectomy to the recording of dysphagia was $7.1 \pm 4.2$ years (SD) with a peak incidence at $4-5$ years $[12,17,18]$. By the time dysphagia develops, indicating significant esophageal involvement, the breast carcinoma is usually widespread. In the present study the dysphagia occurred approximately 4 years after initial detection of the breast carcinoma.

The radiologic features of a secondary esophageal tumor are clearly dependent upon its route of spread to the esophagus. The tumors of a contiguous organ directly spreading to the esophagus show typical changes of malignant tumor involvement that are at times indistinguishable from a primary esophageal carcinoma. However, the obvious primary tumors in the contiguous organ pose no problem in establishing the diagnosis. The tumors spreading via mediastinal nodes and secondarily invading the esophagus show nodular indentation, compression, deviation, rigid segmental narrowing, and even ulceration of the esophagus.

Hematogenous metastases to the esophagus usually pose a diagnostic challenge and commonly present as a short esophageal stricture with normal or minimally irregular mucosa. Occasionally, long segments of involvement may occur. Such strictures may taper asymmetrically and may be con- 
fused with benign peptic strictures. The shorter stricture involving the middle third of the esophagus should be differentiated from Barrett's stricture. A history of gastroesophageal reflux, hiatal hernia, and other supporting features of Barrett's esophagus are usually helpful in this differentiation [34]. When only 1 wall of the esophagus is involved by the metastatic tumor, it may simulate mediastinal lymphadenopathy or other benign mediastinal masses. A metastatic submucosal tumor mass may simulate a benign submucosal lesion such as leiomyoma. When the tumor infiltration progresses and involves the esophagus circumferentially, it may simulate a primary esophageal carcinoma $[3,14,23,24]$.

The phenomenon of esophageal dysmotility and aperistalsis, as observed in 1 of our patients, had been previously reported by. Simeone et al. [35]. Although they proposed that metastatic tumor involvement of the myenteric plexus was responsible for esophageal dysmotility in their patient and seems to be the case in some cases, this explanation of esophageal motor dysfunction has not yet been completely accepted and established by other investigators [36]. In our patient, metastatic tumor was found involving the myenteric plexus of the esophagus at autopsy. A secondary form of achalasia, clinically indistinguishable from the primary idiopathic form, has been reported in tumors of the gastric cardia and a variety of other neoplasms involving the distal esophagus [37-39]. We have previously reported an incidence of secondary achalasia of $20-25 \%$ in gastric cardiac carcinoma, $3 \%$ in primary squamous cell carcinoma of the distal esophagus, and $8 \%$ in Barrett's-type adenocarcinoma of the esophagus [7]. The 5 cases of secondary achalasia in the present series were due to primary tumor of the gastric cardia in 4 and to colonic cancer metastasis to the gastroesophageal region in 1.

Varicoid appearance due to a submucosal metastatic lesion from prostate carcinoma has been recently reported [17]. This appearance, though commonly seen in primary esophageal malignant tumors (Barrett's-type adenocarcinoma $40 \%$ and squamous cell carcinoma 5\%) [7,35], was not seen in any of our patients with secondary esophageal neoplasms. Most malignant polypoid tumors of the esophagus are usually spindle cell squamous carcinoma or sarcoma [40]. Metastatic melanoma presenting as large polypoid intraluminal mass in the esophagus has been reported [26-28].

In evaluating the efficacy of single- versus double-contrast studies, we have found no appreciable difference in their diagnostic yield. The mucosal detail was unquestionably superior with double contrast studies. Computed tomography (CT) was useful in the evaluation of the esophageal wall thickening, and extraesophageal, mediastinal, pulmonary, and chest wall abnormalities. However, in suggesting the diagnosis of secondary neoplasm of the esophagus, CT was of limited value.

Endoscopy and biopsy specimens of metastatic esophageal tumors usually show normal or inflamed mucosa and are reported to be positive for tumor in only $50 \%$ of cases [9, 15, 17, 22, 41-43]. Because of the increased incidence of esophageal perforation, some authors do not advocate these procedures for patients with a history of breast carcinoma who present with esophageal symptoms and show radiographic evidence of esophageal involvement [43]. They recommend treating these patients empirically with radiation therapy.

In summary, a comprehensive clinical and radiologic review of 62 pathologically proven cases of secondary neoplasms of the esophagus is reported. This information should further assist clinicians in correctly diagnosing metastatic esophageal tumor and therefore improve patient management [44-45].

Acknowledgments. The author thanks Ms. Cathy Hicks and Ms. Sylvia Chappell from the Medical Information Department for data collection, and Mr. Peter Hedlesky for excellent secretarial assistance.

\section{References}

1. Toreson WE: Secondary carcinoma of the esophagus, as a cause of dysphagia. Arch Pathol 38:82-84, 1944

2. Atkins JP: Metastatic carcinoma to the esophagus: endoscopic considerations with special reference to carcinoma of the breast. Ann Otolaryngol $75: 356-367,1966$

3. Sasson L: Metastatic neoplasms of esophagus simulating primary carcinoma. JAMA $174: 2075-2076,1960$

4. Fisher MS: Metastasis to the esophagus. Gastrointest Radiol $1: 249-251,1976$

5. Seaman WB, Wells J, Flood C: Diagnostic problems of esophageal cancer: relationship to achalasia and hiatus hernia. Am J Roentgenol 90:778-791, 1963

6. Agha FP, Whitehouse WM: Carcinoma of the esophagus: its varied radiologic features. Mt Sinai J Med 81:430-441, 1984

7. Agha FP: Barrett carcinoma of the esophagus: clinical and radiographic analysis of 34 cases. $A J R$ 145:41-46, 1985

8. Steiner H, Lammer J, Hackle A: Lymphatic metastases to the esophagus. Gastrointest Radiol 9:1-4, 1984

9. Roark GD, Schoppe LE: Painful dysphagia from infiltrating oat cell carcinoma. J Clin Gastroenterol 5:331-334, 1983

10. Inoshita T, Youngberg GA, Dekoos PT: Esophageal metastasis from a peripheral lung carcinoma masquerading as a primary esophageal tumor. $J$ Surg Oncol 24:49-52, 1983

11. Luomanen RKJ, Watson WL: Autopsy findings. In Watson WL (ed): Lung Cancer: A Study of Five Thousand Memorial Hospital Cases. St Louis: C.V. Mosby, 1968, pp 505-510

12. Holyoke ED, Nemotro T, Dao TL: Esophageal metastasis 
and dysphagia in patients with carcinoma of the breast. J Surg Oncol 1:97-107, 1969

13. Sanborn EB, Beattie ES Jr, Slaughter DP: Secondary neoplasms of the mediastinum. $J$ Thorac Surg 35:678-682, 1958

14. de La Pava S, Nigogosyan C, Pickeren TW, Cabrera A: Metastasis of the esophagus. Cancer 16:48-50, 1963

15. Ward P: Pulmonary and esophageal presentations of pancreatic carcinoma. Br J Radiol 37:27-33, 1964

16. Polk HC, Camp FA, Walker AW: Dysphagia and esophageal stenosis: manifestations of metastatic mammary cancer. Cancer 20(2):2002-2007, 1967

17. Anderson MF, Harell GS: Secondary esophageal tumors. AJR $135: 1243-1246,1980$

18. Phadke M, Rao U, Takita H: Metastatic tumors of the esophagus. NY State Med J 76:963-965, 1976

19. Gore RM, Sparberg M: Metastatic carcinoma of the prostate to the esophagus. Am J Gastroenterol 77:358-359, 1982

20. Zarian LP, Berliner L, Redmond P: Metastatic endometrial carcinoma to the esophagus. Am J Gastroenterol 78:9-11, 1983

21. Boccardo F, Merlano M, Canobbio L, Rosso R, Aste H: Esophageal involvement in breast cancer: report of six cases. Tumori $68: 149-153,1982$

22. Orringer MB, Skinner DB: Unusual presentations of primary and secondary esophageal malignancies. Ann Thorac Surg 11: 305-314, 1971

23. Skin MS, Ho KJ: Metastatic cancer masquerading as primary esophageal carcinoma: a roentgenologic pitfall. Alabama J Med Sci 15:174-177, 1978

24. Gross P, Freedman LJ: Obstructing secondary carcinoma of the esophagus. Arch Pathol 33:361-364, 1942

25. Biller HF, Diktaban T, Fink W, Lawson W: Breast carcinoma metastasizing to the cervical esophagus. Larynscope 92:999-1000, 1982

26. Seuhs OW: Malignant melanoma of the esophagus. Ann Otol Rhinol Laryngol 70:1140-1147, 1961

27. Raven RW, Dawson I: Malignant melanoma of the oesophagus. Br J Surg 51:551-555, 1964

28. Wood CB, Wood RAB: Metastatic malignant melanoma of the esophagus. Dig Dis 20:786-789, 1975

29. Agha FP, Schnitzer B: Esophageal involvement in lymphoma. Am J Gastroenterol 80:412-416, 1985

30. Garusi G, Donati E: Carcinoma metastatico dell esofago. Fracastoro 52:117-138, 1969
31. Agha FP, Weatherbee L, Sams JS: Verrucous carcinoma of the esophagus. Am J Gastroenterol 79:844-849, 1984

32. Stankey RM, Roshe J, Sogocio RM: Carcinoma of the lung and dysphagia. Chest 55:13-17, 1969

33. Longston L, Laws JW: Dysphagia in carcinoma of the pancreas. I Faculty Radiol 6:134-138, 1954

34. Agha FP: Radiologic diagnosis of Barrett's esophagus: a critical analysis of 65 cases. Gastrointest Radiol 11(2):123-130, 1986

35. Simeone J, Burrell M, Toffler R: Esophageal aperistalsis secondary to metastatic invasion of the myenteric plexus. Am J Roentgenol 127:862-864, 1976

36. Serebro HA, Venkatachalam B, Prentice RS, Newman HW, Beck IT: Possible pathogenesis of motility changes in diffuse esophageal spasm associated with gastric carcinoma. Can Med Assoc J 102:1257-1259, 1970

37. Tucker HJ, Snape WJ Jr, Cohen S: Achalasia secondary to carcinoma: manometric and clinical features. Ann Intern Med 89:315-318, 1978

38. Schulze KS, Goresky CA, Jabbari M, Lough J : Esophageal achalasia associated with gastric carcinoma: lack of evidence for wide spread plexus destruction. Can Med Assoc J 112:857-864, 1975

39. Davis JA, Kantrowitz PA, Chandler HL, Schatzki SC: Reversible achalasia due to reticulum cell sarcoma. $N$ Engl $J$ Med 293:130-132, 1975

40. Agha FP, Keren DF: Spindle cell squamous carcinoma of the esophagus: a tumor with biphasic morphology. $A J R$ 145: 541-546, 1985

41. Faivre J, Bory R, Moulinier B: Benign tumors of the esophagus: value of endoscopy. Endoscopy 10:264, 1978

42. Delpre G, Kadish U, Gianz I, Avidor I : Endoscopic biopsy diagnosis of oat cell carcinoma of the lung penetrating the esophagus. Gastrointest Endosc 26:104-106, 1980

43. Biller HF, Diktaban T, Fink W, Lawson W: Breast carcinoma metastasizing to the cervical esophagus. Laryngoscope 92:999-1000, 1982

44. Agha FP, Orringer MB: Colonic interposition: radiographic evaluation. AJR 142:703-708, 1984

45. Agha FP, Orringer MB, Amendola MA: Gastric interposition following transhiatal esophagectomy: radiographic evaluation. Gastrointest Radiol 10:17-24, 1985

Received: July 8, 1986; accepted: September 24, 1986 